The district general hospital in Leicester has undergone a facelift since I was last there, replacing the previous institutional look with touches of humanity, colour, and interest - preparation for trust status perhaps?

\section{Fair and representative service?}

On the downside there was evidence of polarisation between fundholders and non-fundholders. Some practitioners whose practices were too small to qualify for the scheme felt bitter, excluded, and frustrated that their patients were being disadvantaged by a system over which they had no control. Such divisions of opinion were causing difficulties in the functioning of local medical committees.

In at least two of the areas I visited the regional health authority and some of the first wave fundholders were wrangling over the savings accrued during the first year. Over $£ 100000$ was at stake in two cases, and the authority's attempts to claw back some of this were being resisted fiercely. Even the enthusiasts for fundholding realised that the lid was sinking on health expenditure. As the system beds down and budgets tighten the opportunities for innovation and experimentation will steadily diminish. In a few years time the fundholders may have very little room to manoeuvre but will still have to cope with the burden of administering their fund. All the fundholders I spoke to admitted that the scheme had increased the number of meetings they had to attend, both within and without the practice. In some areas fundholders had formed liaison groups and were meeting regularly to share experiences and develop their collective expertise. In one town, however, second wave fundholders had been told to fend for themselves by those in the first wave.
I became aware of two further concerns, one from regional and district health planners and one from patients; both related to the increased power of the fundholders. The Health of the Nation spells out a clear strategy for public health policy, ${ }^{3}$ and many regional and district health authorities have mapped out their local plans. Conflict may arise if a large fundholding practice decides to pursue its own health priorities or ignore those of the local district health authority. Similarly, there is no obligation on fundholding practices to consult with their patients over how they will manage their fund and how any savings will be used. Yet the consequences of these decisions, as in the ophthalmology example mentioned above, can have profound effects on patients both inside and outside the practice. I became slightly unnerved by the frequent reassurances I was given by fundholders that they wouldn't do anything to "upset the applecart" or disadvantage their colleagues' patients.

Nobody really knows what the patients think about all this. A recent survey showed that over $40 \%$ of patients did not even know about the NHS reforms, let alone fundholding. Indeed in one practice I visited the patients held a Tupperware party to raise money to "help" their practice-believing that fundholding meant that the practitioners had to raise their own funds. Fundholding has acted as a catalyst for change in Britain's general practice community-the ultimate outcome of the experiment remains to be seen.

1 McAvoy BR. Heartsink Hotel. $B M Y$ 1989;298:968.

2 Glennerster H, Matsaganis M, Owens P. A foothold for fundholding. $A$ preliminary report on the introduction of GP fundholding. London: King's Fund preliminary report on the introduction of

3 Department of Health. The health of the nation: a strategy for health in England. London: HMSO, 1992. (Cm 1986.)

\title{
General practitioner fundholding: experience in Grampian
}

\author{
I C F Wisely
}

Proposals for fundholding were greeted with scepticism by many general practitioners, and in Scotland the BMA persuaded the government to allow a scheme to test the arrangements as a demonstration project operating "shadow" practice funds. This allowed the six selected practices to set up administrative and computer systems without the worry of dealing with real money. The shadow fundholding scheme has since been extended to small practices and to a trial of fundholding for all services except accident and emergency. The six practices in the original pilot have all become fundholders and are beginning to effect improvements in the service to their patients. However, with more practices becoming fundholders negotiating contracts with providers is becoming increasingly complicated and more time and money needs to be put into this aspect.

When the radical proposals on general practitioner fundholding were put forward three years ago they were not enthusiastically received by most of the medical profession. The proposals were believed to be "an attempt to cash limit a demand led service which will damage the doctor/patient relationship and be detrimental to patient care." In Scotland, however, the approach was different. A paper which I and colleagues in Grampian prepared for Scottish General Medical Services Committee posed the questions does this present an opportunity for general practice to have greater influence in the provision of health care for our patients? does it put general practice in the driving seat in helping to determine the range and quality of health service provision? or might it constitute an intolerable administrative burden on the constrained resources of an increasingly cash limited primary care service? ${ }^{2}$

In a characteristically pragmatic way, the BMA in Scotland persuaded the government to allow the proposals to be tested. A shadow fundholding exercise was agreed that would be independently evaluated to assess the effects on the care of patients and look at the administration structures, consulting patterns, and use of doctors' time.

\section{Shadow fundholding}

Six groups of general practitioners in the north east of Scotland were identified for the exercise in the first three months of 1990-five in Grampian and one in Tayside. The evaluation was and continues to be conducted by the Department of General Practice of the University of Edinburgh under Professor John Howie. The exercise was regarded by the then minister for health in Scotland, Michael Forsyth, as a piece of "action" research, the results of which would be made known at intervals during the evaluation. In fact, the first report appeared in July 1992 and was mainly a description of the evaluation process. ${ }^{3}$ Its summary pointed out that around 10 years would be needed to appreciate the full implications of such a fundamental change in the organisation of health services-so much
I C F Wisely, general

practitioner

BMF 1993;306:695-7 


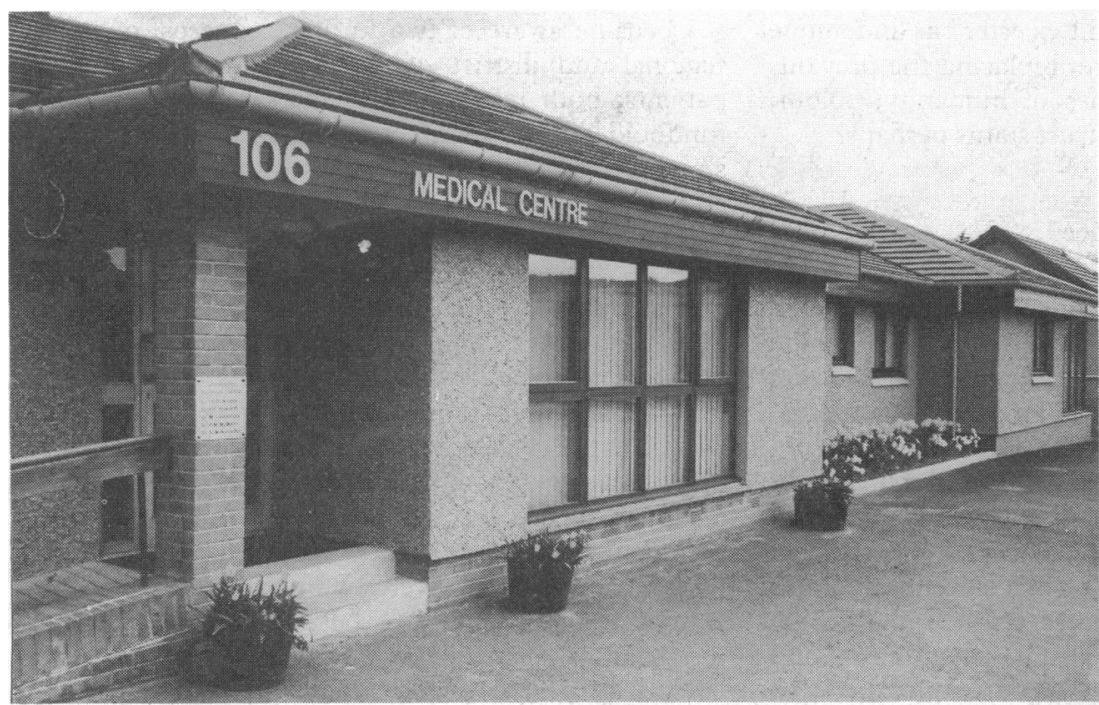

Brimmond Medical Group's experiment with "total" fundholding may point the way ahead

for action research. However, publication of a second report is imminent.

The shadow fundholding exercise was focused in Grampian because of the readiness and willing cooperation of the health board and the enthusiasm of practices of suitable size in Grampian to test out fundholding. Relationships between practices and the primary care division in Grampian have traditionally been close and officials have, on the whole, been supportive of efforts to ensure high standards of general practice.

The exercise allowed the practices, health board, and hospitals to work together with the Department of Health to develop fundholding without the anxieties of dealing in real money. In particular, it enabled the practices to gain experience and confidence in setting up computer systems and staffing arrangements before committing themselves to fundholding. Some of the difficulties encountered in England have arisen from miscalculations in setting funds, because of general practitioners' uncertainty about costs. In Grampian difficulties with the GPass computer system delayed the development of fundholding, and these problems are still being overcome. However, the initial experience was sufficiently encouraging for all the practices to proceed to real fundholding in October 1991.

\section{Further developments}

Fundholding was initially limited to practices with list sizes of at least 11000 patients, which meant that few practices in Scotland were eligible. The minimum list size was subsequently lowered to 9000 patients and has now been further reduced to 6000 . Twelve smaller practices were recruited to the shadow fundholding exercise in 1991 to test the feasibility of fundholding with smaller list sizes. In addition, my practice is participating in a scheme that involves fundholding for the whole range of hospital and community services with the exception of accident and emergency and sexually transmitted disease clinics. This is designed to test the feasibility of extending fundholding to cover all services and not just the limited range of services at present included-which represents only snpiy $20 \%$ of services purchased from providers. On paper we have a nominal fund of $£ 2 \cdot 3 \mathrm{~m}$ covering our 8000 patients.

My practice has not encountered serious practical problems different from those of other fundholders and it seems to remove some of the difficulties of the existing scheme in that it resolves the problem of what referrals are within the range of services that can be purchased. The administrative burden is increased but the processes are the same as those already in place for fundholding. Hospitals have to provide costings for those procedures, admissions, and care not included in the fundholding scheme. I have found this quite revealing - $£ 28000$ a year for geriatric NHS long stay and over $£ 30000$ a year for psychogeriatric long stay. With certain safeguards for patients who, for example, may require liver transplants in Philadelphia full range fundholding seems a realistic possibility.

\section{Enabling general practitioners}

For me however, the biggest eye opener was when I joined the fundholder group in Grampian and their meetings with the provider units. These meetings focused on services provided and on quality issues with a view to modifying contracts to improve the service to patients. Issues discussed included waiting times, return of letters and reports to practices, and the need for outpatients to be seen by a consultant. Experience on statutory advisory committees to the health board has shown me how slow and often ineffectual they are. Hospital services were developed without general practitioners being asked whether they were required and often at the expense of the more routine but essential treatment our patients required. Most general practitioners accepted that the service delivered was what you got and I have often had to persuade the patient to accept that. It was therefore very refreshing to find a group of general practitioners meeting with managers and spelling out precisely what they wanted and, through the contracting process, beginning to see the possibility of achieving it.

I will give you one example of general practitioners' influence. One of the hospitals in Grampian had spare capacity in radiology and made a presentation to the fundholding group. Referrals would be seen within a week and reports sent out the same day, by fax if necessary. The other and main hospital providing radiology had a waiting time of up to nine weeks with no prospect of the additional staff needed to reduce this. Yet within a month it had received additional funding and increased sessions and would be able to meet demands previously unattainable.

So what is the current position in Grampian? The five practices that took part in the shadow exercise became real fundholders in October 1991 and two other practices are participating in the small practice shadow exercise. Other practices have applied to become fundholders so that in April 1993 there will be 25 fundholding practices involving 145 of the 320 general practitioners in Grampian covering 248000 or $47 \%$ of the population. Still more practices intend to become fundholders in 1994 .

\section{Negotiating contracts}

The growth in fundholding poses problems for negotiations and the first moves in setting up the Grampian Association of Fundholding Practices are under way. There are also to be three subgroups of monitoring committees which will ensure adherence to contracts. The executive committee of the association will negotiate the broad contractual issues with providers with detail being resolved directly between fundholding practices and providers. Providers include the private sector, which is keen to compete with the NHS and match costs. Opportunities to enter into contracts with providers outside Grampian exist and practices are looking to develop services in house.

The health board, which negotiates contracts for non-fundholders, is to be represented in the negotiations between providers and fundholders. This will keep the board informed of fundholders' efforts to 
secure high standards and improved quality of care. It is also proposed to include a non-fundholding general practitioner on the committee as it has been a policy to try to ensure that two tier service does not develop. It remains to be seen whether this is practicable. Provider units have expressed fears that fundholders might seek advantage through contracts. As the contracting process evolves individual practices might try to make their contracts more specific, but identifying patients from such practices to meet different contractual demands might prove expensive for the provider units. This should result in fundholders setting the pace and others benefiting.

A fundamental problem is funding the development of the contracting process. Operating a consortium approach will require some form of management structure among general practitioners. Yet most existing fundholders find they do not have the available money as their management fees are fully committed within their practices. One of the major trusts in
Grampian is seeking $£ 1.5 \mathrm{~m}$ to develop contract setting and monitoring and has given a contract to a firm of management consultants to handle contracting issues with fundholders. From the general practice side this matter is being urgently discussed with both the health board and management executive.

In conclusion, I hope you can see the enormous challenge fundholding is posing, and how it is an opportunity to make the health service responsive to our needs as general practitioners acting on behalf of our patients. The huge investment in computers, staff, and administration has the potential to improve the health service by making it more responsive to patients' needs and raising awareness of costs.

1 Beecham L. Harmful effects of practice budgets. $B M \mathcal{F} 1989 ; 298: 1316$

2 British Medical Association. Annual report of council 1989-90. London: BMA: 4-23.

3 Howie JGR, Heaney DJ, Maxwell M, Porter AMD, Hopton JL, Light LJ. The Scottish general practice shadow fund-holding project. Health Bulletin 1992;50(4):316-28.

\section{The fundholding debate: should practices reconsider the decision not to fundhold?}

\section{Duncan Keeley}

We are entering a period of deterioration in health care services. The waste and inefficiency predicted by opponents of the introduction of market mechanisms into the NHS are already becoming evident. Rapidly increasing administrative costs are contributing to reductions in service despite increased expenditure. Unrealistic assumptions are being made about the extent to which — and the speed with which - the need for hospitals can be reduced by technological advance and improvements in primary care.

For primary care the most painful consequences of the reforms stem from the cash limiting of services in the face of rising demands and costs. Cash limits will in future apply to fundholders and non-fundholders alike. The very generous terms on offer to early fundholders will not continue: the crisis in the economy and the ensuing pressure on public spending will accelerate the move to greater stringency in this area. Many fundholding practices are already making loud protest at the reduced funds on offer as regions move to more equitable methods of allocation based on capitation.

In imagining what it would be like to be fundholders in future we should assume that overall adequacy of funding for health care will be less than we have previously known. The key question is whether greater freedom to decide on the distribution of funding between drugs, staff pay, referrals, and community care will be a boon or a burden. We should consider whether taking on this role, in a context of inadequate overall expenditure, might not increase our administrative workload and the level of stress from our clinical work and adversely affect our relationships with our patients, our staff, and each other.

Many practices have so far opted not to take the inducements to fundhold, and some have invested a considerable amount of time and energy into alternative methods of organising general practitioners' input into purchasing decisions. Has the time come to change course? I think not: these are the reasons why.

Thame, Oxfordshire OX9 3JZ

Duncan Keeley, general

practitioner

$B M \mathcal{F} 1993 ; 306: 697-8$

\section{Reasons for not fundholding}

(1) Greatly increased administrative workload-Even with the existing generous management and computer- isation allowances, fundholding involves general practitioners in considerable extra administrative work, over and above that already entailed by the new contract. With an extension of the services covered by the fund, and a reduction in management allowances as more practices take funds, this additional workload will increase and the rewards will dwindle. Few of us truly enjoy administrative work, and the time that we spend on it is lost from direct contact with our patients -or our families.

(2) Conflict with the general practitioner's role as the patient's advocate-Fundholding gives general practitioners an explicit and visible responsibility for rationing the health services made available to their own patients. This conflict of interest may undermine our patients' trust that our decisions on whether or not to treat, investigate, or refer are based solely on their needs rather than on what the fund can afford. Such distrust may extend to the suspicion that our decisions may be influenced by personal financial self interest. This perception, however unfounded it may be, has the potential to complicate many consultations every working day of our lives. The more inadequate that overall funding of services becomes, the more this problem will become a reality. For patients, continued trust in the basis for their doctor's decisions is worth more than the possibility of quicker access to elective surgery. The fact that we already participate in certain ways in what are effectively rationing decisions does not constitute an argument for greatly increasing the scope and visibility of that role.

(3) Implicit acceptance of responsibility for providing a wide range of services to our patients-In taking a fund we accept responsibility for purchasing hospital services, drugs, and now community care on behalf of our patients. As the services provided become less adequate we will find that the perceived responsibility for these inadequacies will also be laid at our door. Government will be very keen to do this, just as governors will be blamed for poor schools, local authorities for poor local public services, and so on. A key theme of policy in recent years has been to maximise the extent to which other agencies than government itself can be held responsible for inadequacies in public sector services. We would be most 